\title{
PolíticA, ePISTEMOLOGÍA Y PEDAGOGÍA: EL MÉTODO INDUCTIVO INTERCULTURAL EN una escuela tseltal de Chiapas, MéXico
}

\author{
Politics, Epistemology and Pedagogy: The Intercultural Inductive Method in a Tseltal School of Chiapas, Mexico \\ Stefano Claudio Sartorello
}

Resumen: Se analizan los principales aspectos de la educación con enfoque intercultural en América Latina, se plantea un posicionamiento crítico sobre ello, y se presentan los principios políticos, epistémicos y pedagógicos que caracterizan el método inductivo intercultural (MII). Posteriormente se analiza su implementación en los procesos de enseñanza-aprendizaje que se desarrollan en una escuela tseltal de Chiapas y se reflexiona acerca de sus alcances y limitaciones.

Palabras clave: educación intercultural, interculturalidad, política educacional, epistemología, investigación pedagógica.

Abstract: After analyzing primary aspects of intercultural education in Latin America from a critical position, this article presents the political, epistemic and pedagogical principles that characterize the intercultural inductive method (IIM). In the second part, the article analyzes how this method is implemented in the teaching and learning processes of a tseltal school in Chiapas and examines its success and limitations.

Keywords: intercultural education, interculturality, educational politic, epistemology, educational research.

Stefano Claudio Sartorello, doctor en Educación por la Universidad Iberoamericana de la Ciudad de México. Estancia posdoctoral CONACyT en el Centro de Investigaciones y Estudios Superiores en Antropología Social, Sede Distrito Federal, México. Temas de especialización: educación intercultural, pedagogías indígenas, epistemologías emergentes y metodologías colaborativas y horizontales. Correo electrónico: stepol_2000@yahoo.com.
Enviado a dictamen: 14 de abril de 2015.

Aprobación: 22 de junio de 2015.

Revisiones: 1. 


\section{De eso que llaman educación intercultural...}

L a educación con enfoque intercultural constituye uno de los campos emergentes en la producción del conocimiento educativo, y su importancia en México y América Latina ha sido cada vez más relevante a partir de los primeros trabajos realizados durante los años setenta del siglo XX. ${ }^{l}$ La amplia producción académica que se reporta en el volumen Multiculturalismo y educación 2002-2012 (Bertely, Dietz y Díaz, 2013), editado por el Consejo Mexicano de Investigación Educativa (COMIE), muestra la relevancia que el concepto de interculturalidad ha asumido en el ámbito educativo. Justo por ello, antes de presentar el caso de estudio que se analiza en este artículo es necesario un posicionamiento al interior de este debate, cargado de implicaciones no sólo pedagógicas, sino políticas y epistémicas.

Considero que la interculturalidad aplicada al ámbito educativo no es un concepto ni homogéneo ni unidireccional, sino más bien un término polisémico en constante negociación y definición. En cuanto tal, no se sustenta en una base de significados estables ni necesariamente compartidos, sino en sentidos que representan un abanico de posiciones, tanto individuales como colectivas, tanto oficiales como alternativas, a menudo en conflicto entre sí. Por ello considero que la interculturalidad es un "significante" que, lejos de entenderse como valor absoluto, adquiere múltiples significados en relación con las perspectivas política, social y epistémica desde las cuales se define. En tanto significante, no puede entenderse como un concepto neutro, sino como referente de significados histórica y políticamente producidos. Definir la interculturalidad, por lo tanto, conlleva un posicionamiento político frente a la realidad social. Es así como al inicio de este texto definiré desde dónde me posiciono cuando hago referencia a la educación intercultural. Para ello retomo a Luís Enrique López (2009), quien, al reflexionar acerca de las políticas educativas con enfoque intercultural que se han generado en América Latina a lo largo de las tres últimas décadas, identifica dos direccionalidades:
Una [...] producto de la motivación estatal o académica o de alguna ONG no indígena [...] va de arriba hacia abajo. En contraposición a ella, la segunda se caracteriza por la agencia indígena, que marca una direccionalidad de abajo hacia arriba, cuando la iniciativa surge de una organización de base o de algún otro tipo de liderazgo indígena, la cual gradualmente es asumida o incorporada con modificaciones o no por el Estado (López, 2009: 11).

La diferencia epistémica que caracteriza el locus de enunciación de las propuestas educativas interculturales implementadas "desde arriba" o generadas "desde abajo" es destacada por Catherine Walsh (2002), quien añade otros elementos relevantes para los fines de esta diferenciación:

[...] dentro del debate sobre la interculturalidad están en juego perspectivas que, por un lado, intentan naturalizar y armonizar las relaciones culturales a partir de la matriz hegemónica y dominante (el centro, la verdad o la esencia universal del Estado nacional globalizado) y, por el otro, perspectivas que denuncian el carácter político, social y conflictivo de estas relaciones (Walsh, 2002: 116).

La primera perspectiva se relaciona con la apertura estratégica hacia la diversidad cultural que han desarrollado varios gobiernos latinoamericanos en las dos últimas décadas del siglo XX, y que Héctor DíazPolanco (2006) ha denominado "etnofagia estatal". Ésta implica "el abandono de los programas y acciones explícitamente encaminados a destruir la cultura de los grupos étnicos y, en cambio, la adopción de un proyecto de más largo plazo que apuesta al efecto absorbente y asimilador de las múltiples fuerzas que pone en juego el sistema" (Diáz-Polanco, 2006: 160). Esta nueva estrategia integracionista implica el reconocimiento por parte de los gobiernos latinoamericanos de la existencia de grupos étnicos en el territorio nacional, cada uno con valores y creencias culturales distintos. Su enfoque es la "diversidad en la unidad" y plantea el reconocimiento - limitado- de diversos grupos 
étnicos dentro de lo nacional. Al mismo tiempo, sin embargo, se caracteriza por la adopción de "modelos socioeconómicos que minan la identidad étnica de los pueblos indios. Es lo que puede llamarse la estrategia del indigenismo etnofágico" (Diáz-Polanco, 2006: 162).

Por el contrario, la segunda perspectiva se refiere a procesos educativos interculturales que se inician desde la acción local de comunidades, organizaciones y pueblos indígenas, a menudo acompañados por académicos comprometidos con sus proyectos políticos que buscan producir cambios no sólo en la esfera educativa y cultural, sino también en la económica y política, transformando las relaciones asimétricas (Gasché, 2008a) entre los grupos hegemónicos y los pueblos indígenas al interior de los Estados-nación latinoamericanos. Esta posición crítica:

[...] argumenta que las diferencias, en la práctica concreta, no parten de la etnicidad en sí, sino de subjetividad y un locus de enunciación definidos por y construidos en la experiencia de subalternización social, política y cultural de grupos, pero también de conocimientos (Walsh, 2012: 124).

Es así como, al posicionarme en el debate sobre educación con enfoque intercultural en Latinoamérica, me parece relevante marcar una distinción entre:

a. Una concepción neo-indigenista y etnofágica(DiázPolanco, 2006) que resulta funcional al modelo de Estado-nación neoliberal ya que, siguiendo la tradición del multiculturalismo anglosajón (Taylor, 1993), concibe las políticas interculturales como mecanismos asistenciales que contribuyen al proceso de integración — subordinada — de los pueblos indígenas.

b. Una concepción alternativa que parte de una crítica política y epistémica hacia el sistema neoliberal hegemónicoy la racionalidad occidental y que, desde una visión altermundista, considera que la interculturalidad en general, y la educación intercultural en específico, son un derecho y un medio para lograr la reproducción de las culturas indígenas, así como una estrategia de sus movimientos y organizaciones para contribuir a la construcción de procesos autonómicos $y$, en lo que atañe al ámbito educativo, para generar conocimientos educativos propios y tener el control epistémico sobre la calidad de la educación que se imparte en las escuelas donde se forman sus hijos.

La primera tendencia formaría parte de las políticas implementadas por instituciones multinacionales del capitalismo neoliberal — como el Fondo Monetario Internacional (FMI), el Banco Mundial (BM) y la Organización para la Cooperación y el Desarrollo Económico (OCDE), entre otras-y de los gobiernos nacionales latinoamericanos que hicieron propio el discurso neoliberal para dar continuidad a las políticas multiculturalistas implementadas desde finales de los años ochenta del siglo XX y asumir el liderazgo del proyecto intercultural. Aunque siguen diseñando políticas educativas a partir de una racionalidad meramente económica (Gentili, 2004; Frigotto, 2004; Coraggio y Torres, 1997), estos actores hegemónicos han generado un discurso que conduce a oficializar y retorizar la interculturalidad haciéndola cada día más parecida al multiculturalismo neoliberal. ${ }^{2}$

En contraste con esta concepción neoliberal y neoindigenista de la interculturalidad, personalmenteme identifico con la segunda tendencia en tanto académico comprometido con los pueblos y organizaciones indígenas chiapanecos y mexicanos con los que colaboro desde hace más de diez años, dado que se trata de una tendencia representativa de concepciones críticas de la interculturalidad que brotan de las luchas de los pueblos indígenas y de la sociedad civil nacional e internacional, y reivindican nuevas formas de democracia y de ciudadanía más participativas e incluyentes, así como relaciones socioeconómicas equitativas dirigidas a modificar las profundas asimetrías estructurales entre pueblos indígenas y sectores hegemónicos de las sociedades nacionales y regionales. Dicha tendencia cuestiona el status quo vigente, al manifestar cómo la educación intercultural no sólo es una decisión pedagógica, sino 
que abarca también dimensiones políticas, económicas y epistémicas relacionadas con la forma en la que se conciben las relaciones interculturales y la ciudadanía en los estados latinoamericanos. ${ }^{3}$

Es por ello que, en las reflexiones que desarrollaré en las páginas siguientes, y que se sustentan en el trabajo político-educativo realizado en y desde Chiapas con los integrantes de la Unión de Maestros de la Nueva Educación para México y Educadores Independientes ${ }^{4}$ —UNEM/EI, de aquí en adelante-, me referiré a tres dimensiones de la educación con enfoque intercultural estrictamente relacionadas entre sí: la política, la epistémica y la pedagógica. Estas son fundamentales para comprender los procesos educativos que se desarrollan con el método inductivo intercultural (MII de aquí en adelante), acuñado por Jorge Gasché (2008a y 2008b), en diferentes escuelas indígenas de Chiapas y, en colaboración con los integrantes de la Red de Educación Inductiva Intercultural (REDIIN), ${ }^{5}$ en otros estados de la República mexicana - Puebla, Oxaca, Michoacán y Yucatán — yde Brasil—Roraima, Minas Gerais y Bahía-

En cuanto enfoque político, epistémico y pedagógico, en el MII se define la interculturalidad a partir de una filosofía política crítica en la que se pone énfasis en las relaciones de poder asimétricas entre sociedad y cultura nacional, y sociedades y culturas indígenas:

No podemos pensar la interculturalidad sin la dominación/sumisión. Hablar de la interculturalidad como de una relación horizontal, no es más que un eufemismo para disfrazar relaciones verticales. La interculturalidad no es algo que hay que crear en el futuro, como algunos teóricos lo asumen, la interculturalidad existe ahora y ha existido en América desde la conquista. Pero la dominación/ sumisión imprime a la relación intercultural, por un lado, condiciones económicas, sociales, políticas y legales, y por el otro, disposiciones, actitudes y valores asimétricos, desiguales pero complementarios y que en su complementariedad se reiteran y refuerzan diariamente a través de las conductas rutinarias, esquemáticas entre sujetos dominados y sujetos sumisos (Gasché, 2008a: 373-374).
Como destaca Gasché, la dominación-sumisión que caracteriza las relaciones interculturales entre sociedad nacional y sociedades indígenas se expresa en términos tanto objetivos, como subjetivos. Muestra tajante de lo primero es, por ejemplo, la negativa del Gobierno mexicano a reconocer constitucionalmente a las comunidades indígenas como "entidades de derecho público" y no únicamente como "sujetos del interés público", desconociendo de esta forma la autonomía política plasmada en los Acuerdos de San Andrés. ${ }^{6}$ Pero la dominación-sumisión no sólo es un fenómeno objetivo, sino que también tiene su cara subjetiva en las conductas de algunas personas indígenas que, al encontrarse en el medio urbano o al relacionarse con algún kaxlan, ${ }^{7}$ suelen sentir vergüenza de hablar su lengua nativa o de reconocer prácticas culturales propias que, cuando se encuentran en su comunidad, con su gente, reproducen diariamente:

Es justamente esta ambivalencia que explicita la relación asimétrica que manifiesta la desigualdad entre sociedad nacional e indígena y la dominación de la una sobre la otra, dominación que se realiza en la persona misma del indígena, en su subjetividad (Gasché, 2004: 13).

No es casualidad que esta concepción de la interculturalidad haya encontrado terreno fértil en Chiapas y se haya apropiado de ella una organización multiétnica como la UNEM/EI, que surgió a raíz del levantamiento armado del Ejercito Zapatista de Liberación Nacional (EZLN) en 1994 y que se ha desarrollado en Chiapas en un entorno sociocultural y político marcado por el "conflicto intercultural" (Bertely, 2006) entre las organizaciones indígenas independientes y el Gobierno mexicano y, en general, entre la cultura maya y la kaxlan. En un contexto sociopolítico conflictivo como el chiapaneco, el ámbito educativo no ha representado una excepción. Es un hecho que, a partir de 1994 y paralelamente a los proyectos educativos autónomos promovidos por el EZLN (Gómez, 2002 y 2009; Gutiérrez, 2005; Núñez, 2005; Baronnet, 2009), diferentes sectores de la población indígena chiapaneca 
no declaradamente zapatistas pero que simpatizan con su propuesta política, como es el caso de los educadores independientes asociados a la UNEM, han desarrollado proyectos educativos interculturales críticos a las políticas educativas implementadas por las instituciones oficiales. Amparándose en el Convenio 169 de la Organización Internacional del Trabajo (OIT) y en los Acuerdos de San Andrés, y asesorados por investigadores y académicos inconformes con la visión oficial de la educación, en diferentes regiones del estado de Chiapas algunas organizaciones indígenas como la UNEM/EI, el colectivo Las Abejas (Bertely, 2004) y el Programa Educación Comunitaria Indígena para el Desarrollo Autónomo-ECIDEA (Bertely, 2009) han gestado proyectos educativos interculturales alternativos. A pesar de su visión crítica hacia la educación oficial, estas organizaciones no han renunciado a buscar el reconocimiento oficial de sus propuestas educativas para, desde abajo, incidir en la política educativa intercultural de México, activando procesos de "apropiación étnica de la escolarización oficial" (Bertely y González, 2004: 4).

\section{El método inductivo intercultural (MII)}

No obstante su "desafortunado" nombre de pila, el MII (Gasché, 2008a y 2008b) no es un conjunto ordenado y rígido de reglas, procedimientos y herramientas pedagógicas para organizar los procesos de enseñanzaaprendizaje que se realizan "dentro" de un salón de clase, sino un enfoque político, epistémico y pedagógico integral para generar aprendizajes socioculturalmente significativos a partir de las actividades sociales, productivas, rituales y recreativas que los habitantes de una comunidad indígena realizan en el territorio comunitario. Es por ello quelos educadores comunitarios y los acompañantes académicos que trabajamos con este "método" en las escuelas indígenas de México solemos considerarlo como un paradigma, o bien como una filosofía educativa. De esa forma queremos destacar su flexibilidad para adaptarse a diferentes contextos socioculturales y su versatilidad para articularse con las diferentes pedagogías indígenas con las que ha estado interactuando e inter-aprendiendo en tierras mexicanas. Fue acuñado por Jorge Gasché a partir de su experiencia en los años ochenta del siglo pasado como asesor principal del Programa de Formación de Maestros Bilingües de la Amazonía Peruana (FORMABIAP). ${ }^{8}$ Fue en la primera mitad de los años noventa del siglo pasado cuando, al acudir a México por la resonancia del levantamiento armado zapatista, Jorge Gasché empezó a compartir las ideas centrales de este enfoque educativo con académicos e integrantes de diferentes pueblos indígenas de este país, entre los cuales, prácticamente desde un inicio, asumieron un papel fundamental María Bertely, del Centro de Investigaciones y Estudios Superiores en Antropología Social (CIESAS), y los educadores comunitarios tseltales, tsotsiles y ch'oles de la UNEM/EI. A lo largo de más de quince años, estos y otros actores ${ }^{9}$ han desarrollado diferentes proyectos educativos basados en el MII que han abarcado diferentes ámbitos, como la elaboración de textos y materiales educativos (Bertely, 2004 y 2007b), la formación docente (Bertely, 2011; Sartorello, Martínez, y Gómez Pérez, 2013), el diseño curricular (Bertely, 2009; Sartorello, 2014) o la facilitación de procesos de enseñanza-aprendizaje en escuelas indígenas de Chiapas (Sartorello et al., en prensa).

En el caso de quien escribe, conocí el MII gracias a la invitación que me hizo hacia finales de 2003 María Bertely. Mi colaboración con la UNEM/EI ha aumentado a lo largo de este tiempo hasta volverse el eje central de mi trabajo como antropólogo interesado en el campo educativo. En mis andares con el MII, uno de los retos principales que he enfrentado ha sido el acompañamiento a los procesos de enseñanzaaprendizaje que se realizan en las escuelas comunitarias. Sin menoscabo del trabajo de gestión, elaboración de proyectos, búsqueda de financiamientos y difusión que, bajo la coordinación obediente ${ }^{10}$ de María Bertely, hemos realizado los colaboradores no indígenas de la UNEM/EI, el trabajo de acompañamiento en las escuelas ha sido el que más me ha llamado la atención. En ello he encontrado la oportunidad de contribuir - siempre de forma colaborativa, es decir, con la participación activa 
de educadores comunitarios, niños, padres de familia y conocedores comunitarios - a la consolidación del MII en uno de los espacios clave donde se concretan los principios que lo sustentan. Es así como, para aterrizar las consideraciones anteriores, en las siguientes páginas me dedicaré en primer lugar a explicar los principios políticos, epistémicos y pedagógicos del MII y, posteriormente, me concentraré en relatar y analizar los procesos de enseñanza-aprendizaje que se han desarrollado en una escuela tseltal de Chiapas.

Los procesos educativos interculturales que se desarrollan a partir del MII encuentran su punto de partida en las actividades sociales que las y los habitantes — ancianos, adultos, jóvenes y niños- de una comunidad indígena realizan en el territorio comunitario a lo largo de las diferentes temporadas del año. La importancia de estas actividades como fuentes de la cultura indígena ha sido destacada por Gasché (2008b), quien las sustentó no sólo en el enfoque histórico-cultural desarrollado por Lev Vygotsky (1978) y en la teoría de la actividad de Alekséi Leóntiev (1977), sino en los principios que rigen las pedagogías propias de diferentes pueblos indígenas de Latinoamérica. ${ }^{11}$ Recuperando estos principios pedagógicos endógenos, Gasché destaca la importancia del "hacer" y del "inter-aprender" para el proceso de generación de conocimientos indígenas. Es justamente a través de la participación de los niños y niñas en la realización concreta de actividades productivas, alimentarias, rituales, etcétera, que sus familiares realizan en el territorio comunitario, como se generan conocimientos indígenas escolares en el MII, en un proceso inductivo que fomenta la participación activa de los integrantes de la comunidad en los procesos educativos que se desarrollan dentro y fuera de la escuela.

Como mostraré en la última parte de este texto, el MII opera a partir de procesos educativos prácticos e inductivos en los que, como sucede en las pedagogías indígenas, las niñas y niños desarrollan conocimientos, habilidades y valores culturalmente propios "haciendo" ciertas actividades comunitarias con el acompañamiento de comuneros expertos en ellas y de sus maestros, lo que Barbara Rogoff (2003) expresa con el concepto de "participación guiada". ${ }^{2}$ Asimismo, en estos procesos los niños no sólo aprenden de sus maestros y de los adultos que acompañan las actividades, sino que también inter-aprenden entre ellos mismos al intercambiar saberes los niños más chicos y los más grandes, así como suele hacerse en la educación familiar y comunitaria.

Asumiendo que las culturas son sistemas de actividad - modelos materiales de vida - y sistemas de conciencia - un modo de pensar y sentircomplementarios, interdependientes e históricamente situados (Gallegos, 2008: 223), Gasché retoma estos principios pedagógicos indígenas articulándolos con una concepción "sintáctica" de la cultura que define de esta forma:

[...] cultura no es un conjunto de elementos, materiales y espirituales, que se trataría de inventariar y clasificar, para poder observarlos, examinarlos, comentarlos y explicarlos de alguna manera; sino ella es lo que los seres humanos producen en su proceso vivencial diario, en el cual crean sus medios de subsistencia, transformando la naturaleza, cooperando, interactuando y comunicándose entre ellos. En ese sentido, la cultura es la cara manifiesta y el resultado de las actividades humanas (Gasché, 2008: 316).

En particular, la cultura en las sociedades indígenas se manifiesta por medio de las "actividades productivocomunicativas" que "los miembros de una sociedad desarrollan de manera similar para transformar y comprender la realidad" (Gallegos, 2008: 229). Cada pueblo indígena realiza un modelo de actividad que, a través de la enculturación, le ha sido transmitido por las generaciones anteriores y que es funcional en relación con sus necesidades actuales. Este modelo comprende las técnicas particulares y los discursos que dan significado social a las actividades, respondiendo a una forma de ejercicio de la racionalidad y de producción de conocimiento que es propia de su cultura. Es así como, a partir de esta concepción sintáctica de cultura, el conocimiento indígena es considerado: 
[...] un factor productivo funcional que participa en la actividad (al igual que los gestos y las herramientas), que se actualiza constantemente en las actividades que una comunidad realiza y que, en esta actualización, a la vez, se expresa verbalmente (en los discursos que acompañan la actividad), y se vuelve visible, observable (en los materiales manejados, los gestos, las conductas y actitudes de los actores), es decir, en la forma de su ejercicio (Gasché, 2008a: 316).

Es por ello que en el MII se asume que la fuente de la cultura y del conocimiento indígena para la enseñanza escolar es la "actividad", 13 el proceso mediante el cual los actores expresan su cultura participando en una serie de acciones con sus conocimientos, habilidades y valores que, a través de estas acciones, se activan y se objetivan en la interacción con el medio natural y social, haciéndose observables y produciendo efectos y resultados. De esa manera, "se enfoca el conocimiento indígena siempre de manera contextuada en la situación real de su existencia socio-cultural, de su operatividad y funcionalidad" (Gasché, 2008a: 316). Gasché concluye que, para incluir los conocimientos indígenas en el currículo escolar, es necesario integrar la escuela a la vida real de la comunidad a partir de la sistematización del currículo educativo implícito de su cultura, realizando las actividades escolares -o una parte relevante de ellas - fuera del aula y aprovechando pedagógicamente las actividades sociales, productivas, rituales y recreativas que se realizan en el territorio comunitario para generar "conocimientos indígenas y escolares convencionales", ${ }^{14}$ o sea, conocimientos interculturales.

Estas actividades están plasmadas en lo que en el MII se llama "calendario socionatural" de actividades, un instrumento pedagógico muy importante que los educadores de cada escuela elaboran en colaboración con los comuneros y niños de la comunidad, investigando las actividades que se desarrollan en el territorio comunitario. ${ }^{15}$ En ello se plasman las actividades que los hombres y mujeres de la comunidad realizan en cada temporada del año, articulándolas con los indicadores climáticos, vegetales y animales que la caracterizan, plasmando en un mapa socionatural de la comunidad lo que Gasché (2008a y 2008b) hallamado "integración entre sociedad y naturaleza". En la concepción idealtípica ${ }^{16}$ de sociedad indígena que se asume en el MII, ésta representa la característica epistémica más importantes de estas sociedades. Al respecto, es importante hacer una breve digresión para señalar que, a pesar de los acelerados procesos de transformación sociocultural que afectan cada día más sus territorios modificando sus formas de vida y cosmovisiones, la integración entre sociedad y naturaleza sigue siendo la "matriz cultural" de aquellas sociedades indígenas que siguen viviendo en sus territorios originarios ${ }^{17}$ y está directamente relacionada con la filosofía de vida del buen vivir (lekil kuxlejal). ${ }^{18}$ Antonio Paoli (2003) nos explica que el lekil kuxlejal:
No es una utopía porque no se refiere a un sueño inexistente. No, el lekil kuxlejal existió, se ha degradado pero no se ha extinguido y es posible recuperarlo [...] Los tseltales piensan y constatan que el lekil kuxlejal no está eliminado, que está presente en el monte, en el firmamento, en nuestra madre la luna, en nosotros mismos como integración de ch'ulelal (alma) y baketal (cuerpo) y que el lekil kuxlejal puede regenerarse, que es necesario generar instrumentos, mapas y brújulas que orienten esta generación. Para producir estos instrumentos deben tenerse presentes las tradiciones aún arraigadas y en gran medida operantes en la vida social (Paoli, 2003: 221).

Lejos de ser una reliquia del pasado, el lekil kuxlejal forma parte de la construcción de un proyecto político, social y cultural promovido por los movimientos indígenas latinoamericanos contemporáneos que se oponen a las políticas desarrollistas de corte neoliberal implementadas por los gobiernos nacionales, como fue el caso del programa federal Vivir Mejor durante el sexenio 2006-2012 en México. Se trata de un horizonte político-social hacia el que caminan los hombres y mujeres de maíz que, retomando a Miguel Alberto Bartolomé (1997) en su reflexión sobre los procesos de transfiguración cultural, no se resignan a dejar de ser 
lo que eran para seguir existiendo en la actualidad y en el futuro.

Como destacamos en un estudio exploratorio sobre el tema del buen vivir (Sartorello, Ávila y Ávila, 2006) realizado con estudiantes de la Universidad Intercultural de Chiapas (UNICH), el lekil kuxlejal es un estado de vida integral en cuya construcción colaboran los seres humanos y la misma naturaleza que, en la cosmovisión maya, es madre y un ser vivo fuertemente interrelacionado con la sociedad humana con la que interactúa constantemente. ${ }^{19}$ Ahora bien, en el MII esta integración entre sociedad y naturaleza, que se manifiesta en las actividades que los habitantes de las comunidades indígenas realizan en el territorio comunitario, se considera "matriz cultural" de los pueblos indígenas, expresión de un tipo de racionalidad epistémica distinta de la racionalidad occidental.

Detengámonos un momento en este aspecto. Como destaqué en la primera parte de este texto, una de las características principales de las propuestas educativas interculturales alternativas y críticas que surgen desde el seno de las comunidades y organizaciones indígenas es la de generarse a partir de una racionalidad "otra", ontológicamente diferente de la dominante. En el MII esta racionalidad se expresa en la integración entre sociedad humana y naturaleza que, en las sociedades indígenas que siguen viviendo en territorios rurales, determina que una gran parte de las actividades que realizan los habitantes de una comunidad indígena se desarrolle en estrecho contacto con los espacios físicos y simbólicos presentes en el territorio de la comunidad - como las milpas, ríos, cerros, potreros, patios, huertas, caminos, casas, canchas, etcétera-. Es a través de la realización de actividades específicas en espacios territoriales específicos como se generan, reproducen y desarrollan los conocimientos, habilidades y valores propios asociados a cada actividad. Y es justamente aprovechando de forma pedagógica las actividades propias que se realizan en el territorio de una comunidad de acuerdo con cada temporada del año, como en el MII se explicitan los conocimientos, habilidades y valores propios asociados a cada una de ellas. Después de haberse analizado, sistematizado y ampliado - lo que se llama proceso de explicitación-, éstos se articulan con los conocimientos escolares convencionales, generando así conocimientos interculturales construidos desde abajo y desde adentro, o sea, a partir de una racionalidad epistémica propia. En este sentido, es importante señalar que los educadores que trabajamos con el MII somos conscientes de que otra parte muy relevante de los conocimientos, habilidades y valores que, retomando la teoría del control cultural de Guillermo Bonfil (1983), forman parte de la cultura apropiada de los pueblos indígenas contemporáneos, es aprendida fuera del territorio comunitario - como, por ejemplo, en la experiencia de migración hacia centros urbanos y otros territorios regionales, estatales e internacionales-. Somos conscientes de que, al concentrarnos en los conocimientos, habilidades y valores que se generan desde las actividades que los habitantes de las comunidades indígenas realizan en sus territorios ancestrales, estamos excluyendo estos conocimientos apropiados. Sin embargo, al hacerlo queremos contrastar la creciente penetración de estos conocimientos, habilidades y valores dominantes, que son expresión de una racionalidad hegemónica que, por medio de las escuelas oficiales, los medios de comunicación masiva y los procesos migratorios, está debilitando el acervo vivo de conocimientos propios, cimientos de la cultura autónoma de las comunidades indígenas o, como dijo Bonfil (1983; 1988), aquellos recursos culturales propios que un grupo social puede producir y reproducir autónomamente y, en especial, sobre los cuales tiene el poder de decidir cómo utilizar y para qué fines. Fortalecer, desde el ámbito educativo, la cultura autónoma resulta entonces una estrategia política, epistémica y pedagógica para impulsar la:

[...] continuidad histórica de una cultura diferente, en torno a la cual se organiza un proyecto civilizatorio alternativo [...] La afirmación de la cultura propia es, por eso, un componente central, no sólo de cualquier proyecto democrático sino de toda acción que descanse en la convicción de que los hombres lo son por su capacidad creadora (Bonfil, 1983: 299-300). 
Por eso, en el MII se promueven procesos educativos centrados en lo propio, donde la articulación intercultural con los conocimientos, habilidades y valores exógenos se realiza después de haber enfatizado aquello que se considera culturalmente propio.

Aterricemos ahora estas reflexiones analizando los procesos pedagógicos realizados en una escuela tseltal donde se trabaja con el MII.

\section{El MII en una escuela tseltal de Chiapas ${ }^{20}$}

Al revisar la literatura producida a lo largo de la última década sobre los proyectos educativos no oficiales, tanto autónomos como independientes, que se realizan en Chiapas (Gómez-Lara, 2002 y 2009; Núñez, 2005; Gutiérrez, 2005 y 2006; Baronnet, 2009), se podría tener la errónea percepción de que están cerrados a experiencias educativas generadas por organizaciones que, comola UNEM/EI, han colaborado con instituciones oficiales y centros públicos como el CIESAS. Sin embargo, una de las características más interesantes de los proyectos no oficiales, como es el caso de la escuela tseltal a la que me refiero, es más bien su permeabilidad hacia el entorno educativo en el que está inmersa, lo que se refleja en la disposición de sus educadores para inter-aprender de y con otras experiencias que surgen en los márgenes del Estado, pero que son críticas de las políticas educativas diseñadas desde los escritorios de las secretarías de Educación federal y estatal. En el caso de la escuela tseltal, es importante señalar que, a pesar de mantenerse independiente del Estado y sus instituciones educativas, los educadores que en ellas trabajan han buscado alimentary fortalecer sus prácticas educativas con los principios pedagógicos del MII que les han compartido los integrantes de la UNEM/EI, ya que en ello han encontrado una forma muy concreta y operativa de poner en práctica los principios políticos, epistémicos y pedagógicos que rigen su concepción de la educación. Aunque en este texto no pretendo reconstruir la historia de los intercambios y la colaboración que se han dado entre los educadores de la UNEM y los educadores independientes que laboran en escuelas no oficiales de diferentes localidades y municipios de Los
Altos, Selva y Norte de Chiapas, bien vale mencionar que estos procesos han sido constantes a lo largo de los últimos veinte años. Estos intercambios han generado inter-aprendizajes entre propuestas educativas que, como es el caso del "modelo curricular de la UNEM" (Bertely, 2009), comparten con las propuestas generadas desde el movimiento indígena independiente el objetivo de propiciar procesos educativos socioculturalmente relevantes para las niñas y niños indígenas de las escuelas comunitarias, fortaleciendo su arraigo territorial (Sartorello, 2013) y la construcción de autonomías territoriales inspiradas en los principios políticofilosóficos del lekil kuxlejal o buen vivir.

Fue a partir de la investigación de las actividades que se realizan en el territorio de su comunidad como los educadores de esta escuela tseltal identificaron diferentes actividades comunitarias relacionadas con la recolección, el procesamiento y el uso de recursos naturales locales, como la naranja, el maíz o el algodón, por ejemplo, para transformarlas a través del MII en unidades de enseñanza-aprendizaje. Ha sido a partir de la realización concreta de estas actividades en diferentes espacios del territorio comunitario - milpas, patios y cocinas, solares o bosques - como han trabajado distintas áreas del conocimiento escolar convencional de manera integral, relacionándolas en cada momento con elementos sociales, productivos y naturales que forman parte de los recursos culturales propios de la comunidad (Bonfil, 1983; 1988). No es de menor relevancia señalar que, en estas actividades, fueron acompañados por comuneras y comuneros expertos que compartieron sus conocimientos y habilidades específicos con las niñas y niños, participando activamente como "recursos culturales vivos" en el desarrollo de los procesos educativos escolares formales. Asimismo, ha sido gracias al trabajo pedagógico realizado con estas actividades como se han logrado articular los conocimientos, habilidades y valores propios que emergieron en cada actividad, con conocimientos, habilidades y valores relacionados con el currículo escolar formal, lo que ha generado una educación intercultural construida "desde abajo y desde adentro" (Bertely, 2009: 5), es decir, desde un territorio socionatural comunitario considerado 
"matriz cultural" de la cultura tseltal de la comunidad.

Veamos algunos ejemplos concretos de ello retomando las unidades didácticas que hemos diseñado en colaboración con los educadores de esta escuela a partir de las actividades comunitarias que ellos seleccionaron. Estas fueron "pedagogizadas" de acuerdo con los principios del MII, que prevén que la actividad escogida sea expresada en forma escrita a partir de una frase prototípica general que expresa la sintaxis cultural. Esta frase general es: "Nosotros vamos a nuestro territorio a pedir un recurso que trabajamos para satisfacer nuestras necesidades sociales" (Bertely, 2009: 85).

Una de las propiedades más interesantes de esta frase que, como he señalado, expresa lo que Gasché ha denominado "sintaxis cultural", es que articula cuatro ejes generales que, a raíz de la racionalidad epistémica centrada en la integración entre sociedad y naturaleza, resultan ser de fundamental importancia para la generación de conocimientos en las sociedades indígenas. Estos ejes generales son: territorio, recurso natural, técnica y fin social.

Cada uno de estos ejes generales se compone de variables específicas que permiten a los educadores comunitarios profundizar en los conocimientos implícitos en la actividad, procediendo de lo general a lo específico. En la figura l se sintetiza la articulación entre los cuatro ejes generales (en mayúsculas) y se muestran algunas de las principales variables específicas (en minúsculas) que integran cada eje. ${ }^{21}$

Son justamente estos cuatro ejes generales y sus variables específicas los que permiten explicitar los conocimientos, habilidades, técnicas y valores propios que emergen de la actividad comunitaria. Una segunda propiedad de esta frase general estriba en que puede concretizarse en forma de una actividad específica que se lleva a cabo en una comunidad indígena y que el educador puede utilizar para desarrollar actividades pedagógicas con sus alumnos con el acompañamiento de las personas de la comunidad expertas en ellas. En el caso de las actividades seleccionadas por los educadores de esta escuela tseltal, las frases concretas fueron las que se reportan en el cuadro 1 , en el que se destaca en cursiva el eje de generación de conocimientos interculturales correspondiente.

Al convertirla en una frase que expresa una actividad específica, la frase genérica recibe su contenido sociocultural particular y concreto de acuerdo con la actividad seleccionada y el contexto territorial en que se implementa. Además, la frase específica articula, según una lógica propia, la expresión de una racionalidad epistémica que se deriva de la integración sociedad-naturaleza como matriz cultural indígena, con los diferentes elementos naturales, animales, vegetales, minerales o técnicos que intervienen en la actividad y que, analizados en su especificidad, permiten explicitar los conocimientos indígenas presentes en la actividad y, posteriormente, articularlos con conocimientos escolares convencionales para generar conocimientos interculturales. No es de menor importancia señalar que este proceso de explicitación y articulación intercultural no se realiza a partir de una lógica deductiva, sino inductiva, haciendo y participando en actividades culturalmente significativas bajo la guía (Rogoff, 2003) de los educadores y adultos que acompañan la actividad. A través de sus gestos y de preguntas que ayudan al niño a analizar y comprender los procesos que realiza, ${ }^{22}$ éstos acompañan un proceso de aprendizaje que se realiza de forma autónoma y de acuerdo con la edad y la etapa de desarrollo cultural en la que se encuentra cada niño. Al respecto, es interesante observar que la participación diferenciada según la edad y el género de los niños en las actividades que se realizan y se pedagogizan a través del MII permite recuperar procesos de inter-aprendizaje intergeneracionales e intergenéricos que son propios de la pedagogía tseltal ${ }^{23}$ y que no suelen ser aprovechados en las escuelas primarias oficiales, sobre todo en aquellas tradicionales donde las niñas y niños pequeños trabajan aislados de sus hermanos mayores.

Para finalizar esta parte dedicada al funcionamiento del MII y para mostrar algunos ejemplos de los conocimientos que se trabajan por medio de este enfoque educativo, en el cuadro 2 se presentan algunas de las oportunidades de explicitación del conocimiento propio y de articulación intercultural con el currículo oficial que se derivan de las actividades comunitarias arriba mencionadas. 


\section{Política, epistemología y pedagogía en una} propuesta educativa intercultural en Chiapas

Las oportunidades de explicitar los conocimientos propios presentes en las actividades comunitarias y de articularlos con conocimientos escolares convencionales que se muestran en el cuadro 2 son solamente algunos ejemplos de las potencialidades del MII en cuanto enfoque político, epistémico y pedagógico aplicado al campo educativo. Será justamente a partir de estas tres dimensiones que, en la parte conclusiva de este artículo, reflexionaré críticamente acerca de sus alcances y limitaciones.

En relación con la primera dimensión, es menester recordar que el MII se sustenta en una concepción política y crítica de la interculturalidad (Gasché, 2008a) en la que se reivindica el derecho de los pueblos indígenas a una educación propia social y culturalmente significativa y relevante, tal y como se expresa en el Convenio 169 de la OIT y en los Acuerdos de San Andrés. Como señalé anteriormente, por medio del MII los educadores de la UNEM/EI se reapropian de los procesos educativos formales y de un espacio como la escuela, que ha sido y sigue siendo el vehículo de transmisión de modelos sociales, políticos y económicos de corte occidental promovidos por políticas educativas indigenistas y neoindigenistas en las que las culturas indígenas sólo tienen cabida como reliquias del pasado o como ejemplos del folclore popular mexicano. En este sentido, no es de menor importancia señalar la continua búsqueda por parte de la UNEM/EI del reconocimiento por parte del Estado de una propuesta educativa intercultural que dialogue con los conocimientos escolares convencionales, pero que construya este diálogo a partir de lo propio, enfatizando la importancia de que los niños y niñas indígenas practiquen, investiguen y analicen desde adentro la cultura en la que nacieron, mediante la exploración de los conocimientos, saberes y prácticas que emergen de las actividades que se desarrollan en el territorio socionatural comunitario. Aunque esta búsqueda de reconocimiento oficial ha sido fuertemente criticada por el movimiento zapatista y los educadores independientes, que temen ser manipulados y cooptados por las instancias oficiales, considero que es una expresión de la voluntad política de ser reconocidos, en cuanto indígenas, como parte de la nación mexicana lo que, en este sentido, nos remite al famoso lema "iNunca más un México sin nosotros!" con el que los zapatistas proclamaron ante la sociedad nacional e internacional su derecho a ser reconocidos en su diversidad.

Por lo que se refiere a la segunda dimensión de la interculturalidad, que he llamado epistémica apoyándome en los autores que se adscriben a la perspectiva crítica de la interculturalidad revisados en las primeras páginas de este texto, considero que el MII representa una alternativa válida con respeto a la lógica colonial y eurocéntrica de generación de conocimientos que suele caracterizar las propuestas educativas interculturales oficiales. Aunque haya sido tachada de romántica y hasta de esencialista por parte de sectores de la academia que no alcanzan a comprender la dinamicidad implícita en la concepción sintáctica de la cultura indígena que la sustenta, considero que la sintaxis cultural y la teoría de la actividad mediante su articulación con la pedagogía indígena centrada en el "hacer" y en el "inter-aprender" son dos de los elementos más innovadores del MII y lo posicionan como una epistemología alternativa y contrahegemónica. ¿Cómo definir de otra forma un enfoque educativo que propicia la construcción de conocimientos interculturales a partir de la explicitación de los conocimientos propios que emergen de las actividades que los habitantes de una comunidad indígena realizan en su propio territorio de acuerdo con el calendario socionatural? ¿Cómo no darse cuenta de la racionalidad "otra" implícita en la integración sociedad-naturaleza en cuanto matriz cultural que orienta el proceso de generación de conocimientos interculturales?

Finalmente, el análisis crítico de la vertiente pedagógica que expliqué en páginas anteriores merece ser analizado para identificar sus fortalezas, debilidades y necesidades de consolidación. Entre las primeras, cabe resaltar la estrecha relación que el MII establece con una pedagogía indígena centrada en el hacer y en el inter-aprender, en la que los niños realizan aprendizajes 
significativos participando activamente bajo la guía de los adultos en actividades reales y culturalmente relevantes que luego serán analizadas y sistematizadas en el salón de clase, y se usarán como núcleos generadores de las habilidades escolares convencionales que forman parte del bagaje académico que necesitan para seguir formándose y, si lo quieren, llegar a estudiar una carrera en la universidad. Entre las segundas, una de las más apremiantes tiene que ver con el alcance del proceso de articulación entre los conocimientos propios y los escolares convencionales, el cual, como diez años de experiencia con el MII me han mostrado, sigue siendo demasiado dependiente de los conocimientos que el propio educador domina. Mientras que en un principio los conocimientos exógenos venían reflejados principalmente en los libros de textos oficiales que los educadores comunitarios de la UNEM/EI utilizaban para el proceso de articulación - lo que enfatizaba los conocimientos escolares convencionales previstos por la Secretaría de Educación Pública-, pareciera que hoy en día este papel está siendo cada vez más asumido por otra información que los educadores encuentran en internet. Lo que preocupa al respecto de este procedimiento es que, si bien se logra incrementar la cantidad, la calidad y el alcance de la información a disposición de los educadores y, a través de su mediación, de los propios niños, estos recursos parecen demasiado abstractos y difíciles de operativizar en un método que se asume inductivo y que se centra, como las pedagogías indígenas, en aprender haciendo.

¿Cómo lograr una mejor articulación entre estos dos estilos culturales de aprender? ¿Cómo propiciar en los niños indígenas una mejor construcción de conjuntos articulados de conocimientos, habilidades y valores interculturales que les permitan analizar críticamente y modificar de acuerdo con sus necesidades la realidad en la que viven? ¿Cómo propiciar que los niños desarrollen habilidades académicas que les permitan seguir estudiando en los niveles secundario y medio superior hasta acceder a una universidad? No cabe duda que para contestar exhaustivamente a estas y otras preguntas que tienen que ver con las dimensiones política, epistémica y pedagógica de la interculturalidad hace falta seguir trabajando en la consolidación del MII, acompañando a los educadores comunitarios en el trabajo que realizan en sus escuelas con este enfoque educativo y analizando de manera crítica sus alcances y limitaciones.

\section{Notas}

${ }^{1}$ Al referirse a los orígenes de la educación intercultural en América Latina, Luís Enrique López (2009) identifica en el trabajo de los lingüistas-antropólogos venezolanos E. Mosonyi y O. Gonzáles (1974) uno de los primeros intentos de definir la interculturalidad aplicada al campo educativo como "[...] una vía para el mantenimiento del marco de referencia de la cultura original, pero vivificado y puesto al día por la inserción selectiva de configuraciones socioculturales procedentes de sociedades mayoritarias, generalmente nacionales [...] evitando en lo posible la deculturación y la pérdida de valores etnoculturales" (López, 2009: 141).

${ }^{2}$ Como señala Fidel Tubino (2003), la interculturalidad forma parte del discurso oficial de muchos Estados nacionales latinoamericanos. Claudia Briones (2002) destaca que la conversión de los pueblos indígenas en sujetos de derecho internacional forma parte de procesos más amplios que, desde los setenta del siglo $\mathrm{XX}$, vienen instalando consenso hegemónico en torno a la legitimidad de las llamadas políticas de acción afirmativa y discriminación positiva en los países de América Latina. En particular, a partir de la última década del siglo XX los gobiernos latinoamericanos han internalizado un discurso democratizador, igualitario e intercultural, proclamando sus naciones como países multi-pluriculturales y promoviendo en sus programas oficiales propuestas educativas interculturales y bilingües. Esta estrategia formaría parte de un "neoindigenismo" que no puede entenderse fuera de de las políticas neoliberales hegemónicas. Slavoj Zizek (200l) sostiene que el capitalismo global de la actualidad opera una lógica multicultural que incorpora la diferencia mientras que la neutraliza y la vacía de su significado efectivo. En este sentido, el reconocimiento y el respeto de la diversidad cultural se convierten en un componente del capitalismo global, y 
la interculturalidad pensada e implementada desde la hegemonía neoliberal se vuelve un concepto estratégico que sustituye el discurso sobre la pobreza por el discurso sobre la cultura, tratando de esconder el peso y la importancia que tienen la injusticia distributiva, las desigualdades económicas y las relaciones de poder en la construcción de nuevas relaciones interculturales entre los Estados-nación y los pueblos indígenas en América Latina.

${ }^{3}$ Si se analiza del lado de las organizaciones y movimientos indígenas latinoamericanos, la interculturalidad formaría parte de un proyecto político de fortalecimiento y politización de la identidad étnica, de cuestionamiento de la dominación económica, política y simbólica y de las diversas formas de explotación concretas que padecen los pueblos indígenas. En el ámbito educativo, esta concepción de la interculturalidad implicaría combinar valores y conocimientos locales -comunitarios, étnicos- con aquellos que son exigencia de la modernidad occidental, para lograr nuevos recursos que permitan nuevas formas de participación en las respectivas naciones $\mathrm{o}$, mejor dicho, nuevas formas de “ciudadanía étnica” (De la Peña, 1999). López (2009) señala que, en las experiencias interculturales pioneras de Colombia, Bolivia y Ecuador, la emergencia de una agencia cultural indígena se caracterizó paulatinamente por un fuerte cuestionamiento de la ontología del conocimiento escolar. En particular, fue la agencia indígena la que determinó el tránsito de propuestas educativas pensadas "para" los indígenas, hacia otras construidas, primero, "con" ellos, hasta llegar a la situación actual, en la que las propuestas educativas interculturales bilingües son planteadas "desde" ellos mismos. El protagonismo del movimiento indígena determinó quela interculturalidad trascendiera su inicial orientación culturalista y se tiñera de matices políticoeconómicos relacionados con la supervivencia de los pueblos indígenas y con el sentido de la democracia en un país multiétnico. Entre otros autores, Catherine Walsh (2002) nos ayuda a reflexionar sobre los alcances de la interculturalidad como proyecto contrahegemónico caracterizado por un uso político de la cultura que se concibe como campo de batalla ideológico y de lucha por el control de la producción del conocimiento y por la hegemonía cultural y política. La interculturalidad crítica va más allá de la búsqueda de reconocimiento o de inclusión social y apela a cambios profundos en todas las esferas de la sociedad, formando parte de una "política cultural oposicional" en la que es central la diferencia colonial que ha relegado y subalternizado a estos pueblos, sus prácticas y conocimientos, demarcando así la diferenciación entre saberes locales-folclóricos, no-académicos y la universalidad epistémica de la modernidad (Mignolo, 2005). Desde este punto de vista, la educación intercultural se concibe como una praxis contrahegemónica, enfocada en revertir la designación de algunos conocimientos como legítimos y universales y la relegación de otros, especialmente aquellos de los pueblos indígenas relacionados con la naturaleza, el territorio y la ancestralidad, al espacio local de saberes o del mundo de la vida. Todo esto evidencia la existencia de una diferencia no sólo cultural y colonial, sino profundamente epistémica (Mignolo, 2005).

${ }^{4} \mathrm{La}$ UNEM/EI es una organización multiétnica integrada por educadores comunitarios tsotsiles, tseltales y ch'oles de Los Altos, Selva y región Norte de Chiapas que se creó en 1995, en el marco del resurgimiento étnico y de los procesos de apropiación escolar que detonó el levantamiento armado del Ejercito Zapatista de Liberación Nacional (EZLN). A pesar de que varios de sus integrantes, en particular aquellos que se identifican como educadores independientes, comparten sus ideales de lucha, desde su fundación la UNEM ha buscadola interlocución con las instituciones educativas del Estado para incidir desde abajo en la formulación de políticas educativas interculturales alternativas con respecto a los planteamientos oficiales. En sus esfuerzos por generar propuestas y materiales educativos interculturales socioculturalmente relevantes, la UNEM/EI ha trabajado prácticamente desde los inicios con el Centro de Investigaciones y Estudios Superiores en Antropología Social (CIESAS) y, en particular, con las unidades de San Cristóbal de Las Casas (Dr. Ronald Nigh y Mtro. Raúl Gutiérrez) y del Distrito Federal (Dra. María Bertely), lo que la llevó a generar diferentes materiales educativos (Bertely, 
2004; 2007b), una propuesta curricular (Bertely, 2009) y a facilitar procesos de formación docente en Chiapas y en otros estados de la República - Puebla, Oaxaca, Michoacán, Yucatán- (Bertely, 2011), antes de manera independiente y luego en el marco de las actividades del Laboratorio Lengua y Cultura Víctor Franco (LLCVF) del CIESAS. Sobre la historia y trayectoria educativa de la UNEM/EI sugiero revisar: Marstom (1997), Roelofsen (1999), Gutiérrez (2005 y 2006), Bertely (2006, 2007 a y 2013) y Sartorello (2009, 2011 y 2013).

${ }^{5} \mathrm{La}$ REDIIN es un colectivo plural e independiente integrado por más de quinientos maestros, educadores comunitarios -entre los cuales se encuentran los educadores de la UNEM/EI-, investigadores, académicos e integrantes de la sociedad civil, indígenas y no indígenas, que comparten la experiencia de haberse formado en el MII. Fue creada en 2009 por María Bertely (CIESAS) con la finalidad de intercambiar experiencias sobre el MII y construir un espacio colectivo de análisis y reflexión para consolidar y desarrollar este enfoque político, epistémico y pedagógico.

${ }^{6}$ La autonomía plasmada en los Acuerdos de San Andrés implica la definición de un ámbito espacial y la asignación de recursos materiales para que los pueblos indígenas puedan concretar sus derechos, así como un ámbito de distribución de competencias políticas, económicas, sociales, culturales, educativas, judiciales y del manejo de recursos para hacer efectivo el derecho de las comunidades a determinar sus propios proyectos y programas de desarrollo.

7 Como señala José Alejos (1999: 132-133): “[...] para el maya el otro es el kaxlan, el 'castellano', el extranjero, Occidente". El autor explica que kaxlan es la contraparte, el "otro" polifacético con quien se relaciona el indígena maya. Es su referente primordial de identidad étnica, el personaje con quien el indígena ha mantenido las relaciones más intensas y conflictivas a lo largo del tiempo. Como efecto de siglos de dominación y explotación social, económica y cultural, los pueblos indígenas de Chiapas viven un entramado de relaciones con el mundo kaxlan marcado por la lucha y la incomprensión y, así como otros ámbitos de la vida social, el educativo, y la escuela en particular, representa un espacio en donde se desarrollan estas relaciones conflictivas entre indígena y kaxlan, fruto de una incomprensión entre dos culturas, una dominada y otra dominante, entre las que ha sido históricamente muy complicado establecer un diálogo armonioso.

${ }^{8}$ El FORMABIAP es reconocido como uno de los programas más innovadores en la formación de docentes con enfoque intercultural ya que integra en su propuesta curricular la investigación y la docencia. Por más de una década, Jorge Gasché fue, junto con Lucy Trapnell y otros destacados antropólogos, pedagogos y sociolingüistas, uno de los creadores e impulsores de este programa que opera de manera ininterrumpida desde 1988, atendiendo a maestros de alrededor de quince pueblos indígenas amazónicos integrados en la AIDESEP (Asociación Interétnica para el Desarrollo de la Selva Peruana), la más importante confederación indígena amazónica de Perú. Gasché y sus colaboradores desarrollaron el MII a partir de la sistematización de la experiencia realizada en el FORMABIAP. Al respecto véase: ETSA y Gasché (1996), Gasché (2008a y 2008b), Martínez (2008) y Gallegos (2008).

${ }^{9}$ Entre los académicos menciono a Rossana Podestá de la UPN-Puebla, Erika González del CIESAS, Ulrique Keiser delaUPN-Michoacán, Ron Nighy RaúlGutiérrez del CIESAS sureste, Jorge Gasché, Carmen Gallegos y Jessica Martínez del Instituto de Investigaciones de la Amazonía Peruana, Maxim Repetto de la Universidad Federal de Roraima y Lucilene Julia Da Silva de la Universidad Federal de Minas Gerais, Brasil. Entre las instancias financiadoras de estos proyectos figuran organizaciones internacionales (Organización de Estados Iberoamericanos), agencias financiadoras (Fundación Ford, Kellogg) e instituciones educativas federales (Dirección General de Educación Indígena y Coordinación General de Educación Intercultural Bilingüe, ambas dependientes de la Secretaría de Educación Pública) y estatales (Dirección de Educación Indígena de la Secretaría de Educación del Estado de Puebla).

${ }^{10}$ Obediente en cuanto mediada y controlada por los educadores de la UNEM/EI, en un interesante e innovador proceso de negociación continua entre el 
poder formal de los académicos y el poder sustantivo de los propios educadores (Bertely 2013; Bertely, Sartorello y Arcos, 2015).

${ }^{11}$ En el caso de las pedagogías maya tsotsil y tseltal ver los trabajos de Modiano (1974), Freedson y Pérez (1999), Pérez (2003), Rogoff (2003), Paoli (2003), Maurer (1977 y 2011) y De León (2005).

12 Como señala Barbara Rogoff (2003), el desarrollo cognitivo del niño indígena es el resultado de un aprendizaje que ocurre mediante la "participación guiada" en actividades sociales con el acompañamiento de pares y adultos que apoyan y retan el dominio de destrezas y entendimientos. Al participar en una actividad culturalmente estructurada, el niño indígena recibela orientación yel apoyo de una persona con mayor habilidad y experiencia y adquiere nuevas destrezas y habilidades a través de la observación, la imitación, el juego, la práctica guiada y la corrección. Un ejemplo de este proceso de enseñanza-aprendizaje endógeno es el que se realiza en la milpa familiar, uno de los espacios educativos fundamentales en las culturas indígenas, en particular en lo que se refiere a la educación de los hombres. Desde los 6 o 7 años, el padre o, en su ausencia, el abuelo o el hermano mayor (bankilal), suele llevar con frecuencia a sus hijos varones a la milpa familiar, en la que propiciará que los niños experimenten y entiendan diversos procesos complejos para capacitarse para el trabajo productivo.

${ }^{13}$ Gasché destacó la importancia de la actividad durante uno de los talleres de diseño curricular en los cuales se diseñó el modelo curricular de la UNEM/EI (Bertely, 2009): "La comunidad está presente en la escuela por medio de las actividades sociales. Esa es la idea básica de la educación intercultural: partir de la realidad vivencial de cada pueblo y desarrollar a partir de ahí las actividades pedagógicas [...] La palabra actividad se opone a objeto, cosa. [...] Las escuelas convencionales, al hablar de un tema motivador, siempre se refieren a una cosa, algo estático. Ahí nosotros introducimos un cambio fundamental, porque no hablamos de cosas sino de actividades: el aprendizaje no sólo es hablar de una cosa sino hacer. Por eso la escuela debe de ir fuera del aula. El conocimiento no solo es palabra, es gesto, es saber hacer, es conducta [...]. El hacer ya es aprender a hacer, ya el niño está desarrollando ciertas habilidades, por eso es importante no solo hablar de las cosas sino hacerlas. [...] La fuente del conocimiento es la actividad. [...] El primer paso es hacer la actividad y vamos luego -en el aula- a explicitar los conocimientos implícitos -en la actividad-. Los vamos a decir, los vamos a expresar, ordenar, sistematizar. Eso es el proceso de explicitación" (Memoria del Taller de Diseño Curricular realizado en Noviembre 2006 en el CIESAS de San Cristóbal de Las Casas, pp. 6-9).

${ }^{14}$ Por conocimientos indígenas escolares se entienden los conocimientos, habilidades y valores que resultan de la sistematización del currículum implícito de una cultura indígena específica. Por conocimientos escolares convencionales se entienden los conocimientos que suelen ser trabajados en la currícula educativa de las escuelas primarias oficiales.

${ }^{15}$ Diferentes ejemplos de este instrumento pedagógico pueden ser analizados en Bertely (2004 y 2012).

${ }^{16} \mathrm{El}$ ideal-tipo es un instrumento conceptual creado por Max Weber y usado en sociología para aprehender los rasgos esenciales de ciertos fenómenos sociales. Un tipo ideal está formado por la acentuación unidimensional de uno o más puntos de vista y por la cantidad de síntesis de fenómenos concretos difusos que se colocan según estos puntos de vista enfatizados de manera unilateral en una construcción analítica unificada. Dicha construcción mental, puramente conceptual, no puede ser encontrada empíricamente en la realidad. El concepto de tipo ideal es así un instrumento para unificar partes de la realidad elegidas contingentemente desde la base del interés particular del investigador y establecido sobre una valoración subjetiva del aspecto determinado, ordenando la realidad mediante la selección de lo que, desde tal perspectiva, se considera como esencial para los fines de la investigación, sin que por ello los mismos rasgos sean en sí esenciales. Así pues, el contenido del tipo ideal depende de cómo se posiciona ontológica y políticamente el sujeto investigador, de qué ideas guarda frente al fenómeno que analiza.

17 Sobre todo de aquellos sectores indígenas rurales que, resistiendo a aceptar la migración como única 
solución a la pérdida de rentabilidad económica del campo, siguen luchando para construir alternativas políticas, económicas y educativas en sus territorios. En efecto, a pesar de la creciente penetración de la cultura occidental en las sociedades indígenas, la integración entre sociedad y naturaleza "sigue constituyendo un conjunto de referencias normativas fundamentales para conceptualizar y proyectar la sociedad del futuro" (Paoli, 2003: 69) para los pueblos mayas contemporáneos porque es el sustento de una racionalidad propia.

${ }^{18}$ Lekil kuxlejal es una palabra compuesta en la lengua maya tseltal. Kux (vivir), lejal (buscar), lekil (bien). Por lo que lekil kuxlejal puede traducirse como: "buscar vivir bien", "buscar la buena vida".

19 Al respecto, me parece importante señalar las aportaciones de Toledo Llancaqueo (2007), Toledo y Barrera-Bassols (2008) y Boege (2008), entre otros autores que adoptan el término "territorio biocultural", para hacer énfasis en la integración entre sociedades indígenas y naturaleza. Al referirse al territorio socionatural estos autores señalan que, para los pueblos indígenas, el concepto de "territorio" abarca varias dimensiones como la política -que se refiere a la jurisdicción, gobierno, normas y decisiones-, la cultural —como espacio socialmente organizado, significativo culturalmente, en el cual se localizan, distribuyen y organizan las redes sociales de asentamiento y las acciones colectivas de un grupola simbólica - asociada a las peregrinaciones, a los rituales y a los mitos de origen - y la natural —que se refiere a los recursos naturales y a las prácticas agrícolas producidas de manera colectiva y de carácter intergeneracional y acumulativo-. Como señala Boege: "El territorio es para los indígenas una prolongación de la expresión material de la red de relaciones que construye el conocimiento colectivo [...] ya que el territorio y el conocimiento constituyen una unidad indisoluble" (Boege, 2008: 62).

${ }^{20}$ En este artículo no se mencionará el nombre de la escuela tseltal con la que colaboramos. Tampoco se describirán a detalle las actividades pedagógicas que realizaron sus educadores. Únicamente se mencionarán algunos ejemplos de las actividades y las planeaciones que diseñamos en conjunto. Lo anterior ha sido acordado con los educadores, quienes revisaron el presente texto y nos autorizaron a publicar solamente lo que en ello aparece.

${ }^{21}$ Para ver todas las variables que integran cada eje, remito a Bertely (2009).

${ }^{22}$ Eugenio Maurer (2011) explica que una de las formas culturalmente más idóneas de ayudar el aprendizaje de los niños tseltales es la mayéutica, el arte socrático que consiste en "ayudar al discípulo, por medio de preguntas, a "dar a la luz" sus saberes implícitos o a reflexionar sobre lo que ha observado y ha practicado, con lo cual logra una mejor comprensión de la realidad" (Maurer, 2011: 68).

${ }^{23}$ Eugenio Maurer (2011) señala que: "Hay otra forma de aprendizaje, típica de los tseltales: ya jnopbeyjbahtik: nos aprendemos unos a otros. Así, por ejemplo, cuando escuchan un discurso o una plática, la gente comenta entre sí, se preguntan unos a otros y se explican lo que no han entendido bien. Lo mismo sucede en la escuela: los estudiantes, aun los pequeños, dialogan, se preguntan unos a otros y se explican lo que dice el "maestro". Esta pedagogía "mutua" es excelente y muy eficaz, puesto que los pedagogos son los estudiantes mismos" (Maurer, 2011: 67).

\section{Referencias bibliográficas}

AAVV (2009). "Currículum para la educación primaria intercultural bilingüe ECIDEA". En M. Bertely Busquets (coord.) (2009), Sembrando nuestra propia educación intercultural como derecho. Diálogos, experiencias y modelos educativos de dos organizaciones indígenas del estado de Chiapas. México: UNEM, ECIDEA, CIESAS, IIAP, OEI, Ediciones Alcatraz.

Alejos García, J. (1999). Ch'ol / Kaxlan: Identidades étnicas y conflicto agrario en el norte de Chiapas, 1914-1940. México: UNAM.

Baronet, B. (2009). Autonomía y educación indígena: las escuelas zapatistas de las cañadas de la Selva Lacandona de Chiapas, México. Tesis de doctorado, El Colegio de México-Université Sorbonne Nouvelle París III. 
Bartolomé, M.A. (1997). Gente de costumbre y gente de razón. Las identidades étnicas en México. México: Siglo XXI.

Bertely, M. (coord.) (2004). Tarjetas de autoaprendizaje. México: Fondo León Portilla, Premio Bartolomé de Las Casas, CGEIB-SEP, OEI, Fundación Kellogg Editorial Santillana, UNEM, Colectivo Las Abejas, CIESAS, IIAP- Perú.

Bertely, M. y E. González (2004). "Experiencias hacia la interculturalidad de los procesos educativos. Reportes de la década de los noventa". En I. Hernaiz (coord.), Educación en la diversidad: experiencias y desafíos en la educación intercultural bilingüe. Argentina: IIPEUNESCO.

Bertely, M. (2006). "La construcción desde debajo de una nueva educación intercultural bilingüe para México". En L.E. Todd y V. Arredondo (coord.), La educación que México necesita. Visión de expertos. Nuevo León, México: Centro de Altos Estudios e Investigación Pedagógica, CECyTE.

Bertely, M. (2007a). "Educación intercultural para la ciudadanía y la democraciaactiva y solidaria. Una crítica de la otra educación al multiculturalismo neoliberal y comunitarista”. En G. Dietz, G. Mendoza y S. Téllez (ed.), Multiculturalismo, educación intercultural y derechos indígenas en las Américas. Quito: Abya-Yala.

Bertely, M. (coord.) (2007b). Los hombres y las mujeres de maíz. Democracia y derecho indígena para el mundo. México: Fondo Editorial de la PUCP, Fundación Ford, UNEM, CIESAS.

Bertely, M. (coord.) (2009). Sembrando nuestra propia educación intercultural como derecho. Diálogos, experiencias y modelos educativos de dos organizaciones indígenas del estado de Chiapas. México: UNEM, ECIDEA, CIESAS, IIAP, OEI, Ediciones Alcatraz.

Bertely, M. (2013). "Apropiación étnica e intermediación académica. Una experiencia de educación intercultural alternativa en y desde Chiapas". En Gabriel Ascencio Franco (coord.), Teoría y práctica de la educación intercultural en Chiapas. México: PROIMMSE-IIA-UNAM.

Bertely, M., J. Gasché y R. Podestá (coord.) (2008). Educando en la diversidad. Investigaciones y experiencias educativas interculturales y bilingües. Quito: Abya-Yala.
Bertely, M., D. Dietz y G. Díaz (coord.) (2013). Multiculturalismo y educación 2002-201l. México: COMIE-ANUIES.

Bertely, M., S. Sartorello y F. Arcos F. (2015). "Vigilancia, cuidado y control étnico-político. Red de Educación Inductiva Intercultural". En Desacatos. Revista de Antropología Social, núm. 48.

Boege, E. (2008). El patrimonio biocultural de los pueblos indígenas de México. Hacia la conservación in situ de la biodiversidad y agrodiversidad en los territorios indígenas. México: Instituto Nacional de Antropología e Historia, Comisión Nacional para el Desarrollo de los Pueblos Indígenas.

Bonfil Batalla, G. ([1983]2005). “Lo propio y lo ajeno. Una aproximación al problema del control cultural”. En G. Giménez Montiel, Teoría y análisis de la cultura, vol. 2. México: CONACULTA-ICOCULT, pp. 293-300.

Bonfil Batalla, G. (1988). "La teoría del control cultural en el estudio de los procesos étnicos". En Anuario Antropológico, vol. 86. Brasil: Editora Universidad de Brasilia, Tempo Brasileiro, pp. 13-53.

Briones, C. (2002). "Viviendo a la sombra de naciones sin sombra: poéticas y políticas de (auto)marcación de 'lo indígena' en las disputas contemporáneas por el derecho a una educación intercultural". En N. Fuller (ed.), Interculturalidad y política: desafíos y posibilidades. Lima: Red para el Desarrollo de las Ciencias Sociales en el Perú, pp. 381-417.

Coraggio, J.L. y R.M. Torres (1997). La educación según el Banco Mundial; un análisis de sus propuestas y métodos. Buenos Aires: Miño y Dávila Editores.

De La Peña, G. (1999). "Territorio y ciudadanía étnica en la nación globalizada”. En Desacatos. Revista de Antropología Social, vol. 1, núm. 23. México: CIESAS.

De León Pasquel, L. (2005). La llegada del alma: lenguaje, infancia y socialización entre los tzotziles de Zinacantán. México: INAH.

Díaz-Polanco, H.(2006). Elogiodeladiversidad.Globalización, multiculturalismo y etnofagia. México: Siglo XXI.

ETSA y J. Gasché (1996). "Los alcances de la noción de 'cultura' en la educación intercultural. Exploración de un ejemplo: sociedad y cultura bora". En J. Godenzzi Alegre (comp.) (1996), Educación e interculturalidad en los 
Andesy la Amazonía. Perú: Centro de Estudios Regionales Andinos Bartolomé de Las Casas, pp. 187-293.

Freedson González, M. y E. Pérez Pérez (1999). La educación bilingüe-bicultural en Los Altos de Chiapas: una evaluación. México: UNICACH, SEP.

Frigotto, G. (2004). "Los delirios de la razón: crisis del capitalismo y metamorfosis conceptual en el campo educativo". En P. Gentili (coord.), Pedagogía de la exclusión; crítica al neoliberalismo en educación. México: Universidad Autónoma de la Ciudad de México, pp. 113-160.

Gallegos, C. (2008). "El currículum de primaria basado en actividades como instrumento de mediación entre la cultura local y global: una experiencia educativa en la Amazonía peruana”. En M. Bertely, J. Gasché y R. Podestá (coord.), Educandoen la diversidad. Investigaciones y experiencias educativas interculturales y bilingües. Quito: Abya-Yala, pp. 221-254.

Gasché, J. (2008a). "Niños, maestros, comuneros y escritos antropológicos como fuentes de contenidos indígenas escolares y la actividad como punto de partida de los procesos pedagógicos interculturales: Un modelo sintáctico de cultura”. En M. Bertely, J. Gasché y R. Podestá (coord.), Educando en la diversidad. Investigaciones y experiencias educativas interculturales $y$ bilingües. Quito: Abya-Yala, pp. 279-365.

Gasché,J.(2008b). “La motivación políticadelaeducación intercultural indígena y sus exigencias pedagógicas. ¿Hasta dónde abarca la interculturalidad?" En M. Bertely, J. Gasché y R. Podestá (coord.), Educando en la diversidad. Investigaciones y experiencias educativas interculturales y bilingües. Quito: Abya-Yala, pp.367-397.

Gentili, P. (2004). "Adiós a la escuela pública. El desarrollo neoliberal, la violencia del mercado y el destino de la educación de las mayorías". En P. Gentili (coord.), Pedagogía de la exclusión; crítica al neoliberalismo en educación. México: Universidad Autónoma de la Ciudad de México, pp. 339-376.

Gómez-Lara, H. (2009). Indígenas, mexicanos y rebeldes. Procesos educativos y resignificación de identidades en Los Altos de Chiapas. Tesis de doctorado, Universidad de Sevilla, España.

Gómez-Lara, H. (2002). Educación, identidad y género en San Andrés Sakamch'en (Larráinzar), Chiapas. Tesis de Licenciatura en Antropología, Universidad Autónoma de Chiapas, México.

Gutiérrez, R. (2005). Escuela y zapatismo entre los tsotsiles: entre la asimilación y la resistencia. Análisis de proyectos de educación básica oficiales y autónomos. Tesis de maestría, CIESAS, México.

Gutiérrez, R. (2006). "Los zapatistas toman la escuela: recuento de la dinámica educativa indígena en Chiapas (1994-2003)”. En LiminaR. Estudios Sociales y Humanísticos, vol. 4, núm. 1.

Leontiev, A. (1977). Actividad, conciencia y personalidad. S.l.: Digitales Soyuz.

López, L.E. (2009). "Interculturalidad, educación y política en América Latina: perspectivas desde el Sur. Pistas para una investigación comprometida y dialogal". En L.E. López (ed.), Interculturalidad, educación y ciudadanía. Perspectivas latinoamericanas. La Paz, Bolivia: Plural Editores, FUNPROEIB-Andes.

Marstom, A. (1997). La nueva educación: Community Based Education and School Gardens in Chiapas, Mexico. Tesis in parthial fulfillment of ENVS and LALS.

Martínez, J. (2008). "La actividad mediada y los elementos del aprendizaje intercultural a partir de una experiencia educativa con maestros indígenas de la Amazonía peruana”. En María Bertely, Jorge Gasché y Rossana Podestá (coord.), Educando en la diversidad. Investigaciones y experiencias educativas interculturales $y$ bilingües. Quito: Abya-Yala, pp. 255-278.

Maurer, A.E. (1977). “¿Aprender o enseñar? La educación en Takinwits, poblado tseltal de Chiapas". En Revista del Centro de Estudios Educativos, vol. VII, núm. 1, pp. 84-103.

Maurer, A.E. (2011). "iLos tseltales aprenden sin enseñanzas!". En Revista Latinoamericana de Estudios Educativos, vol. XLI, núm. 3-4, pp. 65-7l. México: Centro de Estudios Educativos.

Mignolo, W. (2005). "Cambiando las éticas y las políticas del conocimiento: lógica de la colonialidad y postcolonialidad imperial". En Tabula Rasa, enerodiciembre, núm. 3. Bogotá: Universidad Colegio Mayor de Cundinamarca, pp. 47-72.

Modiano, N. (1974). Educación indígena en Los Altos de Chiapas. México: Instituto Nacional Indigenista. 
Mosonyi, E. y O. Gonzáles (1974). “Ensayo de educación intercultural en la zona arahuaca del Río Negro (Territorio Federal Amazonas), Venezuela". En Actas 39 Congreso Internacional de Americanistas, vol. 5, Lingüística e indigenismo moderno en América Latina. Lima, Instituto de Estudios Peruanos, pp. 307-314.

Núñez, K. (2005). Socialización infantil en dos comunidades ch'oles. Rupturas y continuidades: escuela oficial y escuela autónoma. Tesis de Maestría en Antropología Social, CIESAS, San Cristóbal de Las Casas, Chiapas, México.

Paoli, A. (2003). Educación, autonomía y lekil kuxlejal: aproximaciones sociolingüísticas a la sabiduría de los tseltales. México: Universidad Autónoma MetropolitanaUnidad Xochimilco.

Pérez, E. (2003). La crisis de la educación indígena en el ârea tzotzil. Los Altos de Chiapas. México: UPN, Miguel Ángel Porrúa.

Quijano, A. (1999). "La colonialidad del poder. Cultura y conocimiento en América Latina". En S. Castro Gómez, O. Guardiola-Rivera y C. Millán de Benavides (ed.), Pensar (en) losintersticios. Teoría y práctica de la crítica post colonial. Santa Fe de Bogotá: Centro Editorial Javeriano, pp. 3-28.

Roelofsen, D. (1999). The Construction of Indigenous Education in Chiapas, México: The Case of the UNEM, the Union of Teachers for a New Education in Mexico (Unión de Maestros de la Nueva Educación para México), Tesis Rural Development Sociology. Department of Rural Development Sociology. Weningen University. The Netherlands.

Rogoff, B. (1993). Aprendices del pensamiento. El desarrollo cognitivo en el contexto social. Barcelona: Paidós.

Saltarello, S. (2013). Conflicto, colaboración y coteorización en un proceso intercultural de diseño curricular. Tesis de Doctorado en Educación, Universidad Iberoamericana, México.

Sartorello, S. (2011). "Construir conocimiento desde el territorio propio: el Método Inductivo Intercultural (MII) en el Modelo curricular de educación intercultural bilingüe de la Unión de Maestros de la Nueva Educación para México (UNEM) en Chiapas". En Andrés Fábregas Puig (coord.), Patrimonio, territorio y desarrollo en la Frontera Sur de México. México: Universidad Intercultural de Chiapas, pp. 49-85.

Sartorello, S. (2009). "Una perspectiva crítica sobre interculturalidad y educación intercultural bilingüe: el caso de la Unión de Maestros de la Nueva Educación para México (UNEM) y educadores independientes en Chiapas". En Revista Latinoamericana de Educación Inclusiva, vol. 3, núm. 2. pp. 77-90.

Sartorello, S., A. Ávila y L. Ávila (2012). El Buen Vivir: miradas desde adentro de Chiapas. México: UNICH, IESALC, UNESCO.

Sartorello, S. (2014). "La co-teorización intercultural de un modelo curricular en Chiapas, México". En Revista Mexicana de Investigación Educativa, vol. 19, núm. 60, pp. 73-101.

Sartorello, S., J. Martínez y F. Gómez Pérez (2013). "Modelos alternativos de formación docente. La experiencia de la Red de Educadores Inductivos Interculturales - Rediin - en Chiapas". En Gabriel Ascencio Franco (coord.), Teoría y práctica de la educación intercultural en Chiapas. México: PROIMMSEIIA-UNAM, pp. 159-178.

Sartorello, S. y María Rosendo (en prensa). "Nuestra propia vitamina. El Método Inductivo Intercultural (MII) en una escuela primaria indígena de los Altos de Chiapas, México". En R. Cortina y K. de la Garza (coord.), Educación, pueblos indígenas e interculturalidad en América Latina. Quito: Abya-Yala.

Taylor, C. (1993). El multiculturalismo y la politica del reconocimiento. México: FCE.

Toledo-Llancaqueo, V. (2007). "El nuevo régimen internacional de derechos de propiedad intelectual y los derechos de los pueblos indígenas". En L. Concheiro y F. López (coord.), Biodiversidad y conocimiento tradicional en la sociedad rural. Entre el común y la propiedad privada. México: Centro de Estudios para el Desarrollo Rural Sustentable y la Soberanía Alimentaria, Cámara de Diputados, IX Legislatura.

Toledo, V. y N. Barrera Bassols (2008). La memoria bio-cultural. La importancia ecológica de las sabidurías tradicionales. Barcelona: Icaria.

Tubino, F. (2003). Del interculturalismo funcional al interculturalismo crítico. Perú: Biblioteca Virtual 
RIDEI. Disponible en: http://www.pucp.edu.pe/ ridei/pdfs/inter_funcional.pdf (consultado el 10 de agosto de 2011).

Vygotski, L.S. (1989[1930-34]). El desarrollo de los procesos psicológicos superiores. Barcelona: Crítica.

Walsh, C. (2002). "(De)construir la interculturalidad. Consideraciones críticas desde la política, la colonialidad y los movimientos indígenas y negros en el Ecuador". En N. Fuller (ed.), Interculturalidad y política: desafíos y posibilidades. Lima: Red para el Desarrollo de las Ciencias Sociales en el Perú, pp. 115142.

Zizek, S. (2001). "Multiculturalismo o la lógica cultural del capitalismo multinacional". En F. Jameon y S. Zizek, Estudios culturales. Reflexiones sobre el multiculturalismo. Buenos Aires: Paidos, pp. 137-188. 


\section{Cuadro 1. Unidades didácticas}

- Vamos a la cocina de doña Mari (territorio) a preparar tortilla (técnica) de maíz verdadero (recurso natural) para alimentarnos sanamente (fin social).

- Usemos tierra arenosa y joloch (recurso natural) que está en el patio (territorio) para elaborar adobe (técnica) para construir nuestra casa (fin social).

- Vamos al solar de la casa (territorio) a recolectar (técnica) chinino (recurso natural) para tener nuestro alimento (fin social).

- Vamos al solar (territorio) a cortar (técnica) naranja (recurso natural) para mantener saludable nuestro cuerpo (fin social).

- Busquemos el camino (territorio) del tlacuache (recurso natural) y hagamos una trampa para cazarlo (técnica) y comerlo en caldo (fin social).

- Vamos al solar de la escuela (territorio) para cortar (técnica) algodón (recurso natural) para usarlo en torundas (fin social).

Fuente: elaboración propia.

Cuadro 2. Ejemplos de explicitación y articulación de conocimientos

\section{Actividad}

Vamos a la cocina de doña Mari a preparar tortilla de maíz verdadero para alimentarnos sanamente.

Usemos tierra arenosa y joloch que está en el patio para elaborar adobe para construir nuestra casa.

\section{Conocimientos propios explicitados}

Variedades de maíz criollo, cosmovisión maya, economía campesina y autonomía alimentaria.

Alimentación propia y cuidado de la salud.

Proceso de elaboración de la tortilla.

Tipos de tierra presentes en el territorio comunitario y sus diferentes usos.

Materiales y herramientas (molde de madera) que se usan en la comunidad para fabricación de adobe.

Las casas que usaban nuestros padres y abuelos: formas, materiales y costos. Ventajas y desventajas.
Articulación con conocimientos escolares convencionales

Variedades de maíz transgénico, ideología capitalista, economía neoliberal y mercados de granos básicos, dependencia alimentaria, salud.

Alimentos industrializados y comida chatarra y cuidado de la salud.

Figuras geométricas (círculo y semicírculo), grados, medición del tiempo (reloj), medidas fraccionarias $(1 / 2,1 / 4,1 / 6 \ldots 1 / 60)$. Características geofísicas del suelo. Elementos químicos presentes en el suelo y sus propiedades.

Figuras geométricas: rectángulo y paralelepípedo (cálculo de perímetro, área y volumen).

Las casas se construyen hoy en día en la comunidad: formas, materiales y costos. Ventajas y desventajas. 
Vamos al solar de la casa a recolectar chinino para tener nuestro alimento.

Vamos al solar a cortar naranja para mantener saludable nuestro cuerpo.

Busquemos el camino del tlacuache y hagamos una trampa para cazarlo y comerlo en caldo.
Alimentación propia y cuidado de la salud.

Economía campesina y autonomía alimentaria.

Medicina propia y elementos naturales para la cura de la malaria.

Conocimiento del territorio comunitario y uso de indicadores geográficos propios.

Historia productiva del territorio comunitario.

Ciclo de vida de la planta de la naranja según la cultura local y relación con las fases lunares.

Usos alimentarios de la naranja y beneficios para la salud.

Conocimiento del territorio comunitario y de los animales presentes en ello.

Técnica propia para elaboración de la trampa.

Cuidados y secretos para la caza de los animales del bosque. Importancia de su cuidado.

Cosmovisión propia y nahualismo.

Elaboración del caldo de tlacuache. Usos curativos y rituales de la piel, los dientes y la grasa del tlacuache.
Propiedades del chinino.

Elaboración de un recetario de sus usos alimentarios (lectura y redacción en español y en tseltal).

Medicina occidental y fármacos para la malaria.

Geografía: coordenadas geográficas, elaboración de croquis y mapa del territorio comunitario.

Historia: la época de la finca.

Ciclo de vida de la planta de la naranja según el conocimiento científico.

Importancia de las vitaminas para la salud.

Figuras geométricas (esfera, círculo) y fracciones. Cantidades y peso.

Fauna local y regional.

Tipos de energía. Relación fuerzaenergía.

Consecuencias de la caza y de la depredación de los animales del monte.

Las nuevas religiones en la comunidad.

Recetario de las comidas que se elaboran con la carne del tlacuache (lectura y redacción en español y en tseltal).

Fuente: elaboración propia. 
Figura 1. Articulación entre ejes curriculares en el MII

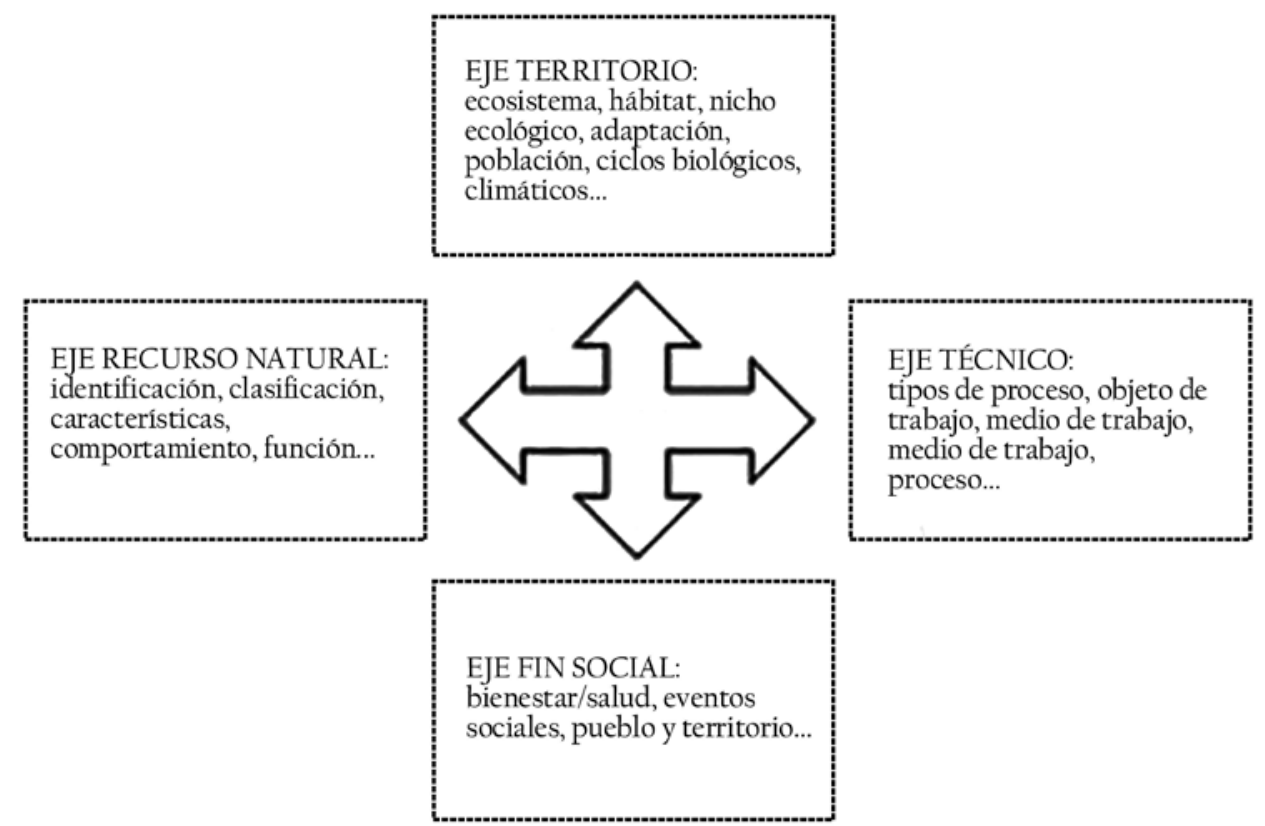

Fuente: elaboración propia. 